\title{
Blickdiagnose
}
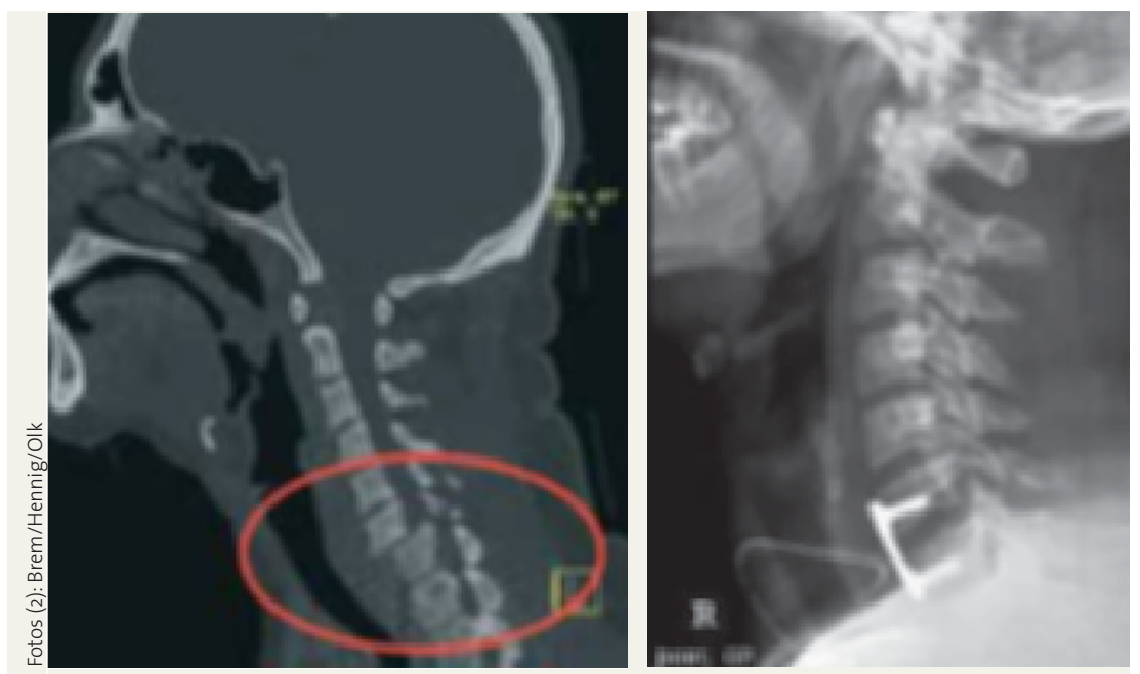

\section{Es passiert in jedem Sommer wieder}

Der 21-jährige Patient war kopfüber in einen Badesee gesprungen und dabei mit dem Kopf auf dem Grund aufgeschlagen. Im Anschluss daran konnte er seine Arme und Beine nicht mehr bewegen. Er wurde sofort von einem engagierten Badegast aus dem Wasser geborgen. Der hinzugeeilte Hausarzt stellte anhand des typischen klinischen Bildes eine Querschnittslähmung unterhalb des Segmentes $\mathrm{C}_{6 / C_{7}}$ mit Sensibilitätsausfällen und spontaner Harnblasenentleerung fest. Dem Patienten wurde unter axialem Zug ein „Stifneck“ zur Immobilisierung angelegt.

Im Anschluss daran erfolgte die schnellstmögliche Verlegung in die nächste unfallchirurgische Klinik. Der schnellstmögliche Transport ist extrem wichtig für die neurologische Erholung und den Repositionserfolg unter der Annahme, dass nur eine spinale Kontusion vorliegt. In der Notaufnahme erfolgte eine CT-Aufnahme, bei der eine Luxationsfraktur der Wirbelkörper $\mathrm{C}_{6}$ und $\mathrm{C}_{7}$ festgestellt wurde (Abb. oben links). Die unmittelbar durchgeführte Reposition erfolgte unter Durchleuchtungskontrolle in Vollnarkose. Die Halswirbelsäule wurde daraufhin mittels Philadelphiakrawatte vorübergehend stabilisiert. In der Klinik wurde eine hochdosierte Kortisonbehandlung nach dem NASCIS-(National Acute Spinal Cord Injury Study Group)-Schema (30 mg/kg Körpergewicht (KG) Methylprednisolon als Bolus, im Anschluss für 23 h 5,4 mg/kg KG) durchgeführt. Im Intervall wurde die HWS chirurgisch mittels winkelstabiler Platte über den Halswirbelkörpern 6 und 7 stabilisiert (Abb. oben rechts). Die neurologischen Ausfallerscheinungen besserten sich leider nur geringfügig. Nach einem Aufenthalt in einer Rehaklinik wird die weitere Betreuung dem Hausarzt übertragen werden. Für den erstversorgenden Hausarzt am Unfallort sollte das primäre Ziel sein, den Hals des Patienten unter Zug zu stabilisieren und ihn möglichst schnell einer unfallchirurgischen Klinik zur Weiterbehandlung zuzuführen.

- M. H. Brem, F. F. Hennig, A. Olk, Abteilung für Unfallchirurgie, Friedrich-AlexanderUniversität Erlangen-Nürnberg

Keyword: acute spinal cord injury 